\title{
Twin-layered Twin Block
}

\author{
${ }^{1}$ Sujala G Durgekar, ${ }^{2}$ Nagaraj Kolur, ${ }^{3}$ Harsha Puttaraju
}

\section{ABSTRACT}

Background: Twin-block appliance is a widely used myofunctional appliance to correct a skeletal discrepancy in growing class II individuals. In patients with deep anterior bite and horizontal growth pattern, the posterior maxillary block has to be trimmed for the active eruption of lower molars to flatten the curve of spee. The upper block is trimmed $1-2 \mathrm{~mm}$ every appointment to encourage lower molar eruption. By keeping the minimal clearance between the lower molar and upper block the tongue is prevented from spreading laterally between the teeth. This might prevent the eruption of mandibular posterior teeth. We have modified the twin block appliance by incorporating two colors alternatively for the maxillary block. This modification acts as a guide for controlled trimming of the upper block.

Conclusion: It is a simple and effective way to prevent the development of lateral open bite during the active phase of twin block therapy.

Clinical significance: Prevents excessive trimming of the blocks hence reduces the risk of developing posterior open bite due to tongue spreading laterally between the teeth.

Keywords: Deep anterior bite, Skeletal class II, Trimming, Twin-block appliance.

How to cite this article: Durgekar SG, Kolur N, Puttaraju H. Twin-layered Twin Block. Int J Experiment Dent Sci 2018;7(2):136138.

Source of support: Nil

Conflict of interest: None

\section{BACKGROUND}

There are plenty of functional appliances available to stimulate the growth of the mandible in young skeletal class II patients. These include bionator, activator, functional regulators, twin block, etc. Among these, twin block appliance is a widely used myofunctional appliance to correct a skeletal discrepancy in growing individuals. ${ }^{1-5}$

${ }^{1}$ Reader, ${ }^{2}$ Clinical Practitioner, ${ }^{3}$ Postgraduate Student

1,3 Department of Orthodontics and Dentofacial Orthopedics, KLE Soceity's Institute of Dental Sciences, Bengaluru, Karnataka, India

${ }^{2}$ Classic Smiles Orthodontic and Dental Care Centre, Bengaluru, Karnataka, India

Corresponding Author: Sujala G Durgekar, Reader, Department of Orthodontics and Dentofacial Orthopedics, KLE Soceity's Institute of Dental Sciences, Bengaluru, Karnataka, India, e-mail: sujala2003@yahoo.com
Twin block appliance consists of maxillary and mandibular acrylic plates with occlusal blocks inclined at 70 degrees to posture the mandible in the forward position. The treatment with the twin block is divided into twophases: ${ }^{6}$ active phase and support phase. In the case of patients with deep bite and horizontal growth pattern; during the active phase of treatment, the upper block is trimmed to encourage e the eruption of lower posteriors to level the occlusal plane. This trimming of maxillary block and eruption of mandibular posterior teeth is beneficial for facial improvement in patients with short anterior facial height. It is trimmed occlusodistally to leave the lower molar 1-2 mm clear of the occlusion to encourage lower molar eruption and reduce overbite. By keeping the minimal clearance between the lower molar and upper block the tongue is prevented from spreading laterally between the teeth. ${ }^{6}$ If trimming of the block is more than the lateral tongue thrusting might develop which will prevent the eruption of lower molars and future settling of occlusion may get prolonged. We have modified the twin block appliance by incorporating two colors alternatively for the maxillary posterior block. This modification acts as a guide for controlled trimming of the upper block.

\section{Technique}

We have modified the twin block by incorporating two colors alternatively for the upper block and called it as 'Twin-layered twin block' (Figs 1 to 3). The thickness of the alternative layer is $1.5-2 \mathrm{~mm}$ thickness each (Fig. 4).

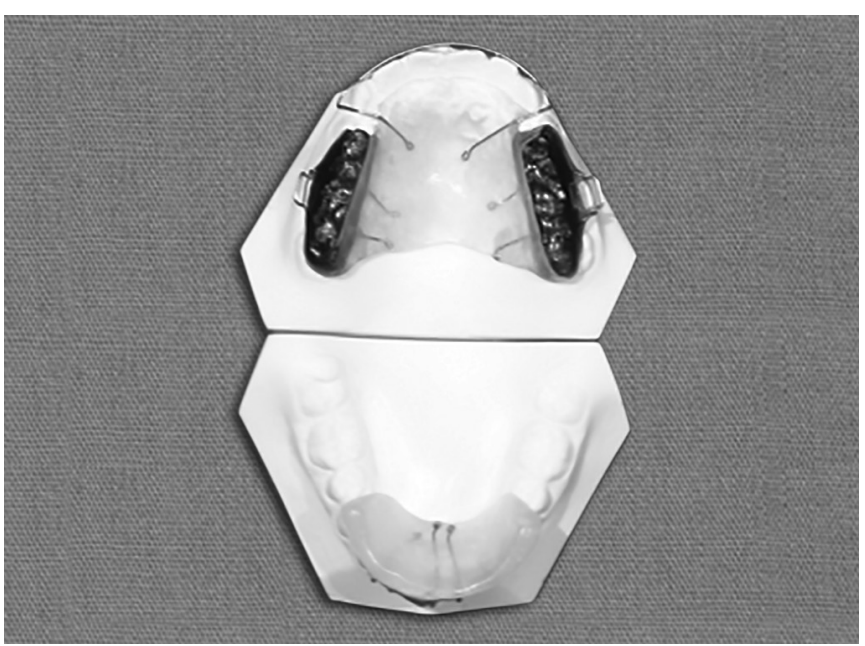

Fig. 1: Layered twin block appliance 

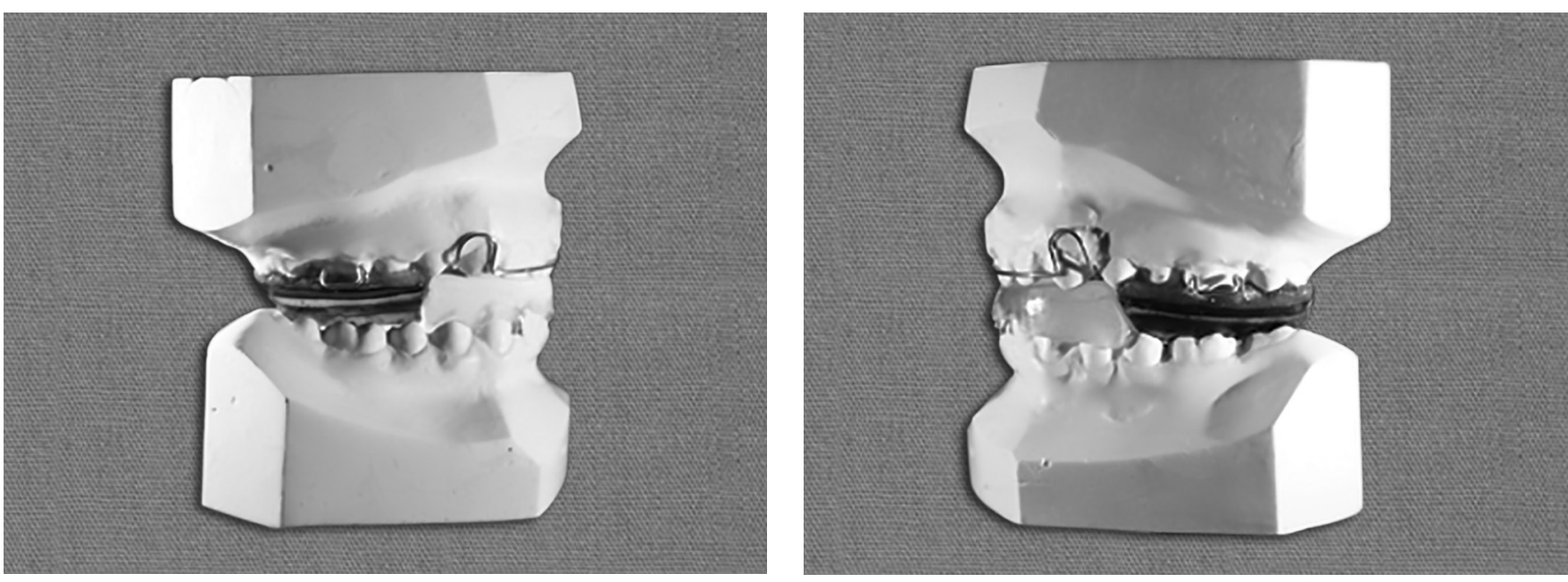

Figs 2 and 3: Lateral views of layered twin block appliance showing alternatively colored upper blocks

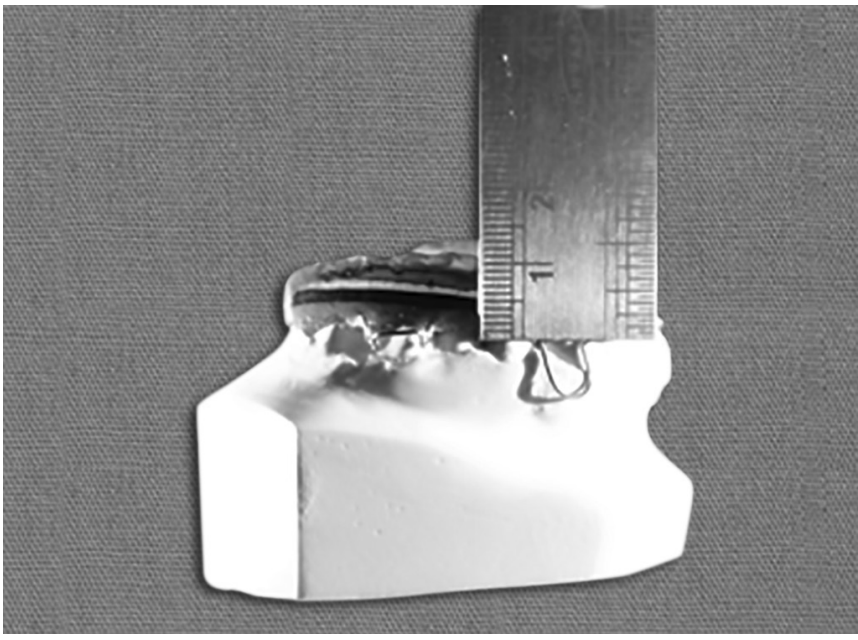

Fig. 4: Thickness of each colored layer is $1.5-2 \mathrm{~mm}$

This color helps differentiate the amount of acrylic block being trimmed to enable lower molar eruption (Fig. 5). Additionally during the active phase of treatment; one glance at the leading edge of the block will help us to know accurately the amount of block trimmed for a molar eruption and the amount of vertical opening in millimeters.

\section{Fabrication of Twin-layered Twin Block}

After bite registration, the working models are mounted on the fixator. Clasps are fabricated on molars and premolars. The conventional maxillary acrylic plate is fabricated. The maxillary occlusal blocks are fabricated on the maxillary acrylic plate, using two different colors alternatively by salt and pepper method. We have used red and blue articulating paper to incorporate respective colors in the self-cure acrylic. Each colored layer in the maxillary block must be of $1.5-2 \mathrm{~mm}$ in thickness. Next, lower block is fabricated which will be angulated at 70

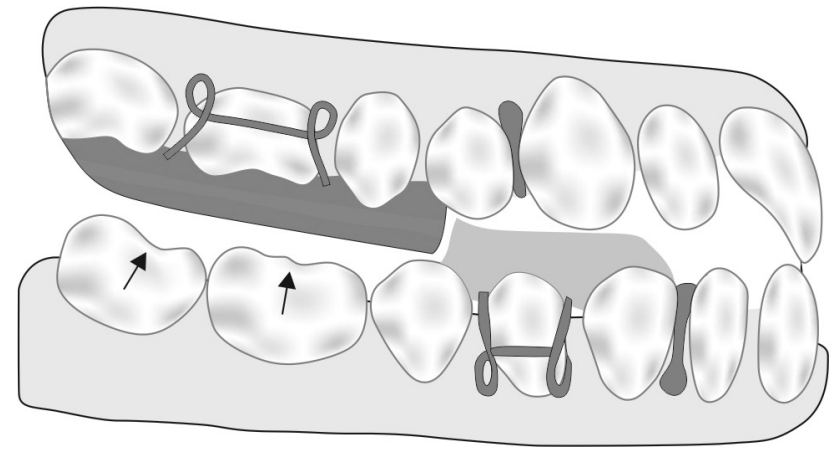

Fig. 5: Schematic diagram showing trimmed maxillary block for lower molar eruption

degrees to the maxillary block. Final finishing of the appliance is done.

\section{Contraindication}

The colored blocks don't play any role in patients with hyper divergent growth pattern with an anterior open bite wherein lower posterior eruption is contraindicated.

\section{DISCUSSION}

Treatment with the twin block appliance brings about reduction of overjet, correction of class II molar relation and improvement in facial profile. The rapid functional correction is achieved by transmitting favorable occlusion forces to the occlusal inclined plane that cover the posterior teeth. At the end of an active phase of the treatment, the aim is to achieve class I occlusion and control of vertical dimension by three-point contacts at incisors and molars in occlusion. Good buccal segment occlusion is the cornerstone of the stability after the arch relationship is achieved. The planned trimming of the posterior block according to the predetermined colors would help to achieve the defined goal of the active phase of twin block therapy. 


\section{CONCLUSION}

It is a simple and effective way to prevent the development of lateral open bite during the active phase of twin block therapy.

\section{CLINICAL SIGNIFICANCE}

Following are the advantages of this modification:

- Prevents excessive trimming of the blocks hence reduces the risk of developing posterior open bite due to tongue spreading laterally between the teeth.

- During the active phase of treatment, one glance at the leading edge of the block will help us know accurately the amount of block trimmed for a molar eruption and the amount of vertical opening in millimeters.

- Improves patient compliance as the blocks are colored.

\section{REFERENCES}

1. Lund DI, Sandler PJ. The effects of twin Blocks: a prospective controlled study. Am J OrthodDentofacial Orthop 1998; 113(1): 104-110.

2. Jamilian A, Show Katbakhsh R, Amiri SS. Treatment effects of the R-appliance and twin block in Class II div 1 malocclusion. Eur J Orthod 2011;33(4):354-358.

3. Mahamad IK, Neela PK, Mascarenhas R, et al. A comparison of twin block and forsus (FRD) functional appalince- a cephalometric study. Int J Orthod Milwaukee Fall 2012;23(3):49-58

4. Yaqoob O, Dibiase AT, Fleming PS, et al. Use of the Clark twin block functional appliance with and without an upper labial bow: a randomized controlled trail. Angle Orthod 2012;82(2): 363-369.

5. Brien $\mathrm{KO}^{\prime}$, Wright J, Conboy F, et al. Effectiveness of early orthodontic treatment with the twin block appliance: a multicenter, randomized, contolled trial. Part 1: dental and skeletal effects. Am J Orthod Dentofacial Orthop 2003;124(3):234-243

6. William J Clark. Twin block therapy: Applications in Dentofacial orthopedics. C.V. Mosby (2th edition) 2002;12-15. 